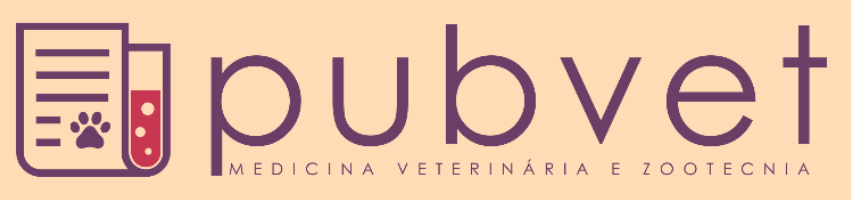

https://doi.org/10.31533/pubvet.v15n01a724.1-8

\title{
Ocorrência, classificação e quantificação de contusões em carcaças de bovinos abatidos em Frigorífico no RS
}

\author{
Paulo Afonso Anezi Junior ${ }^{* \mathbb{9}}$, Paulo Afonso Carvalho ${ }^{2 \Phi}$ \\ ${ }^{I}$ Aluno do curso de pós-graduação e controle de qualidade de alimentos da Universidade Estadual do Rio Grande do Sul (UERGS). Médico \\ Veterinário, Fiscal Estadual Agropecuário SEAPDR - Augusto Pestana - RS, Brasil). \\ ${ }^{2}$ Zootecnista, Dr. Prof. Adjunto da Universidade Estadual do Rio Grande do Sul. Cruz. Alta - Rs, Brasil. \\ *Autor para correspondência, E-mail: pauloanezijr@gmail.com
}

Resumo. As perdas por contusões geram grandes prejuízos à pecuária sem levantamentos confiáveis em nível nacional. O estudo regionalizado buscou evidenciar os fatores que influenciam a ocorrência de contusões em carcaças de animais abatidos em um frigorífico no RS. Foram acompanhados e classificados 42 lotes destinados ao abate, totalizando 816 carcaças avaliadas para severidade, distribuição e quantificação de perdas por contusões, buscando evidenciar a influência de fatores como sexo, categoria animal, distância de transporte, sistema de terminação, características físicas e padrão racial dos animais na ocorrência de hematomas e lesões de graus I, II e III em carcaças. Foram detectadas contusões leves (GI) em 56,25\%, moderadas (GII) em 15,26\% e graves (GIII) em 1,22\% das carcaças avaliadas, totalizando perdas médias de 378,16 g/carcaça. Fêmeas adultas apresentaram maior frequência de lesões e perdas, com diferenças significativas $(\mathrm{P}<0,05)$ em relação aos machos jovens, para diversos parâmetros avaliados. Para o grupo de fêmeas jovens, a presença de aspas influenciou $(\mathrm{P}<0,05)$ na ocorrência de perdas maiores na toalete em relação às fêmeas jovens mochas. A distância de transporte não influenciou na severidade, distribuição ou no volume de perdas na toalete. Fêmeas adultas apresentam maiores perdas em relação às demais categorias avaliadas, com maior severidade e maior frequência de lesões.

Palavras-chave: Abate, carcaças, contusões, fatores predisponentes

\section{Occurrence, classification, and quantification of bruises in carcasses of cattle slaughtered at a slaughterhouse in $R S$}

\begin{abstract}
Losses from bruises cause large losses to livestock without reliable national surveys. The regionalized study sought to highlight the factors that influence the occurrence of bruises in carcasses of animals slaughtered in a slaughterhouse in RS. Forty-two slaughter lots were monitored and classified, totaling 816 carcasses evaluated for severity, distribution, and quantification of losses due to bruises. We sought to demonstrate the influence of factors such as sex and animal category, transport distance, termination system, physical characteristics, and breed of animals in the occurrence of bruises and lesions of grades I, II, and III in carcasses. Of the carcasses evaluated, 56,25\% presented Mild (GI) lesions, moderate (GII) lesions in $15.26 \%$, and severe (GIII) contusions were detected in $1.22 \%$, totaling average losses of $378.16 \mathrm{~g} /$ carcass. Adult females presented a higher frequency of injuries and losses, with significant differences $(\mathrm{P}<0.05)$ compared to young males, for several evaluated parameters. For the group of young females, the horns presence influenced $(\mathrm{P}<0.05)$ the occurrence of larger losses in the toilet compared to young females not horned. Transport distance did not influence the severity, distribution,
\end{abstract}


or volume of toilet losses. Adult females show higher losses compared to the other categories evaluated, with greater severity and higher frequency of injuries.

Keywords: Slaughter, carcasses, bruises, predisposing factors

\section{Introdução}

As exportações brasileiras de carne bovina bateram recorde no ano de 2018, com um volume de 1.639 toneladas de acordo com dados oficiais da Confederação Nacional da Agricultura (Valor Econômico, 2019), totalizando aproximadamente $20 \%$ da produção nacional. Conforme Andrade et al. (2009) a lucratividade da atividade e a qualidade da carne são fatores importantes para pecuaristas, indústria e consumidores. A ocorrência de contusões gera perdas no final do processo produtivo, atingindo a rentabilidade da produção pecuária, o bem-estar dos animais, a qualidade das carcaças e dos produtos produzidos, com perdas em toalete e menor valor comercial das carcaças e cortes. Perdas estimadas com contusões e hematomas somaram mais de 75 milhões de dólares anuais nos Estados Unidos e 20 milhões de dólares na Austrália, no ano 1995 (Braggion \& Silva, 2004). No Brasil, mais de duas décadas depois, são poucos os levantamentos confiáveis a nível nacional. Contudo, pesquisas regionalizadas são desenvolvidas em virtude da grande diversidade e diferentes realidades da pecuária brasileira.

Ocasionadas por impactos teciduais com força necessária para produzir a ruptura de vasos e acúmulo de sangue tecidual, propiciando a formação de hematomas (Hoffman et al., 1998), as contusões podem ser classificadas pela amplitude (Andrade et al., 2008), ou pela profundidade e tecidos atingidos (Cardoso et al., 2011). As contusões de Grau I afetam essencialmente o tecido adiposo, enquanto as contusões de Grau II atingem o tecido adiposo e também os tecidos musculares, ocasionando perdas maiores que as contusões Grau I e prejuízos em cortes específicos. Já as contusões graves, de Grau III, atingem o tecido adiposo, porções musculares profundas e extensas e/ou tecido ósseo, podendo estar acompanhadas de fraturas, ocasionando amplos prejuízos (Cardoso et al., 2011).

Como principais causas de hematomas nas carcaças, Costa et al. (1998) e Ferreira et al. (2010) identificaram lesões devido às agressões diretas, altas lotações, instalações inadequadas, caminhões e estradas em estado inadequado de conservação e animais reativos devido a questões raciais ou por manejo inadequado. Grandin (1996) cita fatores estruturais como pisos escorregadios, falhas de manutenção, correntes de ar e diferentes intensidades de luz em currais e seringas como causas de excitação, estresse e contusões em animais de abate.

Civeira et al. (2006) relatam o processo pré-abate como uma etapa da produção que deve ser mais estudada. Falhas nesse manejo reduzem o bem estar animal e são contrárias aos conceitos de produção sustentável e abate humanitário, resultando em maior probabilidade de lesões em função do tempo de transporte (Andrade et al., 2009). Para Cardoso et al. (2011), a distância de transporte não interferiu na frequência das contusões, citando más condições de estradas e deficiências de instalações como principais causas para uma elevada frequência de lesões.

Métodos agressivos na condução dos animais ocasionam o aumento da ocorrência, da frequência e gravidade das contusões (Mendonça et al., 2016a). Rebagliati et al. (2008) citam o bastão elétrico como causa importante de lesões nas propriedades rurais, no transporte e na condução nos frigoríficos.

O grupo genético também é um fator predisponente a ser considerado, pois determina parte do temperamento dos animais e da qualidade do acabamento das carcaças. As raças zebuínas são mais excitáveis (Grandin, 1996) e mais susceptíveis às contusões (Mendonça et al., 2016b). Mendonça et al. (2016a) citam o tamanho dos chifres como característica física relevante no aumento das lesões préabate. Em estudo realizado no Rio Grande do Sul, comparando lotes de animais aspados Mendonça et al. (2016b) confirmaram maiores perdas econômicas nos animais aspados.

Ao avaliar o efeito do sexo e categorias dos animais, Franco (2013) verificou frequências elevadas de contusões em lotes mistos e lotes de fêmeas, quando comparadas com machos, assim como Nicholson (2008). Por outro lado, Civeira et al. (2006) não encontraram diferenças significativas em estudo realizado no Rio Grande do Sul. Hoffman \& Lühl (2012) relataram índices de contusões maiores em vacas, quando comparadas a novilhos e novilhas, em estudo realizado na África. 
Dentre as diversas variáveis citadas, o sexo dos animais, a composição racial, a categoria animal, a distância de transporte, as características físicas e o sistema de terminação podem ter implicações no bem-estar dos animais e na ocorrência de contusões. Em uma cadeia produtiva extremamente competitiva, a redução destas perdas, através da identificação das causas, adoção de medidas profiláticas e gerenciamento adequado dos animais adquiridos, poderá significar a produtores e indústrias a viabilização de suas atividades produtivas, o alcance de mercados com maior valor agregado e maiores garantias da qualidade dos produtos fornecidos aos consumidores.

Nesse contexto, é importante a utilização de dados gerados a nível local e regional, direcionados às condições produtivas, sistemas de manejo e padrões raciais utilizados em cada região. O presente estudo tem por objetivo efetuar um diagnóstico sobre a ocorrência de contusões nas carcaças de bovinos abatidos em um abatedouro frigorífico localizado na região noroeste do Rio Grande do Sul, originárias do manejo dos animais nas etapas de transporte e abate, assim como classificar as lesões por grau de intensidade, quantificar o peso médio das lesões nos lotes e identificar os locais de ocorrência.

\section{Material e métodos}

O estudo foi conduzido em um Frigorífico registrado no Sistema Estadual de Inspeção (SIE) do Estado do Rio Grande do Sul, com habilitação no Sistema Brasileiro de Inspeção (SISBI), localizado na região Noroeste do Estado do Rio Grande do Sul, no município de Augusto Pestana. A coleta de dados foi realizada concomitantemente com as ações de inspeção sanitária, de acordo com as atribuições do serviço de inspeção estadual. Os lotes abatidos foram classificados de acordo com metodologia estabelecida, buscando evidenciar fatores que apresentam relevância na ocorrência, intensidade e localização das contusões.

Foram avaliadas ocorrência, frequência, distribuição e quantidade de lesões oriundas de contusões em bovinos provenientes da fronteira oeste e região Noroeste do estado do Rio Grande do Sul, totalizando 816 animais avaliados, divididos em 42 lotes. Os lotes foram considerados aptos a participar do estudo no momento em que atenderam aos seguintes critérios:

$\checkmark$ Manejo pré-abate: adequado, atendendo aos critérios estabelecidos pela legislação, transportados em veículo em boas condições, sem superlotação;

$\checkmark$ Tamanho dos lotes: entre 17 e 24 UA (Unidade Animal $=450 \mathrm{Kg}$ de Peso Vivo) dispostos em curral, totalizando ao mínimo lotação de $70 \%$ da área do curral, que apresentam capacidade de lotação máxima de 24 UA`s;

$\checkmark$ Sexo dos animais: homogêneo, lotes compostos exclusivamente por machos ou fêmeas;

$\checkmark$ Padrão racial: homogêneo, de acordo com padrão predominante, com ao menos $80 \%$ dos animais pertencentes ao padrão racial Taurino Europeu (Bos taurus), sendo os lotes que não atendem o critério classificados como Mistos (Bos indicus, cruzamentos);

$\checkmark$ Características físicas: classificados de acordo com a presença ou ausência de chifres, sendo considerados aspados, quando mais de $20 \%$ dos animais do lote apresentaram chifres;

$\checkmark$ Distância do estabelecimento de abate: registro da distância entre propriedade rural e estabelecimento de abate, de acordo com município de origem efetuado em todos os lotes avaliados;

$\checkmark$ Sistema de terminação: os lotes foram classificados por terminação em sistema de confinamento ou sistemas não confinados;

$\checkmark$ Categorias animais: homogêneas, divididos em animais adultos, com ao menos 4 dentes incisivos permanentes, e animais jovens, com menos de 4 dentes permanentes, de acordo com conferência de dentição realizada em linha de inspeção e conferência de documentação de trânsito no exame ante-morten.

As lesões foram quantificadas pela totalidade em cada lote, de acordo com sua distribuição nas carcaças no quarto dianteiro (até $5^{\text {a }}$ costela), na costela/lombo e no traseiro, sendo calculada a média aritmética de cada lote. A classificação da intensidade e frequência das lesões foi feita através de análise 
visual, por observador treinado, classificando os animais como S/L (sem lesões), GI (lesões de intensidade leve), GII (lesões de intensidade moderada) e GIII (lesões graves) de acordo com Cardoso et al. (2011) em todos os animais dos lotes.

A detecção das contusões foi realizada nas linhas de inspeção (exames das meias carcaças cranial e caudal) por colaboradores treinados pelo SIE, sendo encaminhadas após a inspeção para a toalete, com desvios ao Departamento de Inspeção Final (DIF) no caso de contusões GIII, de acordo com as atribuições do serviço de inspeção. As lesões foram retiradas a faca, separadas de acordo com região de ocorrência e pesadas separadamente, com registro em formulário desenvolvido para tal finalidade.

Os registros foram tabulados no Microsoft Excel ${ }^{\circledR}$, para distribuição e análise dos dados de acordo com os critérios descritos. Para análise, os lotes foram distribuídos de acordo com os fatores predisponentes alvos do estudo: características físicas dos animais, sexo, categoria (faixa etária), distância de transporte, padrão racial e sistema de terminação, de acordo com classificação feita na inspeção "ante-morten". A análise estatística foi realizada através do Software STATISTICA ${ }^{\circledR}$ por meio de análise de variância (ANOVA) com nível de significância de 5\% e posterior aplicação do Teste Tukey no caso de rejeição da hipótese. A análise de dispersão visando avaliar correlação de lesões com a distância de transporte dos animais até o frigorífico também foi efetuada.

O estudo foi conduzido sob condições normais e oficiais de acordo com a legislação do SIE. Não ocorreram modificações no manejo ou tecnologia de abate, nem quaisquer intervenções nos animais antes do abate, sendo respeitada a legislação referente às medidas de abate humanitário.

\section{Resultados e discussão}

No presente estudo, foram respeitadas condições adequadas de lotação no transporte e nos currais, com infraestrutura adequada ao manejo dos animais, evitando extremidades pontiagudas, com a condução efetuada por bandeiras e chocalhos, utilizando-se do choque elétrico somente em condições de exceção, conforme recomendado por Braggion \& Silva (2004). Estes cuidados minimizaram a influência do manejo pré-abate nos fatores avaliados.

Dos animais avaliados, $68,02 \%$ apresentaram lesões, valor inferior ao encontrados por Cardoso et al. (2011), Andrade et al. (2008) e Andrade et al. (2009), que apresentaram, respectivamente, percentuais de $90,53 \%, 82 \%, 88,5 \%$ de carcaças contundidas. Entretanto, ocorrências inferiores foram relatadas por Renner (2005), com 49\% de animais contundidos em 20.000 carcaças avaliadas e Dario (2008), com frequência de hematomas em $66 \%$ das 3.112 carcaças avaliadas, demonstrando a variabilidade na ocorrência de contusões sob condições produtivas diversas.

As contusões GI (leves) estiveram presentes em $56,25 \%$ do total das carcaças avaliadas, lesões GII (moderadas) em $15,56 \%$ e as lesões GIII (graves), em 1,22\% das carcaças avaliadas. Em 5,01\% das carcaças foi detectado mais de um grau de lesão. Cardoso et al. (2011) obtiveram resultados semelhantes, com contusões GI como as mais frequentes, seguidas pelas contusões GII, que totalizaram $38,8 \%$, contra apenas $15,56 \%$ no presente estudo.

A média geral de perdas por contusão foi de $378,15 \mathrm{~g} /$ carcaça, inferior ao prejuízo de $500 \mathrm{~g} /$ carcaça relatado por Andrade et al. (2008) em estudo realizado na região do Pantanal (MS), onde as condições de transporte e manejo pré-abate dos animais foram consideradas precárias.

Quanto ao local de ocorrência das lesões, a cada 100 lesões observadas 42,6, 24,0 e 33,4 ocorreram na região do dianteiro, costela/lombo e traseiro, respectivamente. Civeira et al. (2006) observaram que lesões nos quartos dianteiro e traseiro somados correspondiam, em média, a 51 de 100 lesões encontradas na carcaça de machos e fêmeas abatidos em frigoríficos do Rio Grande do Sul. As lesões no dianteiro representaram 96,27 g/carcaça, na região da costela e lombo 143,06 g/carcaça, e no traseiro $138,83 \mathrm{~g} /$ carcaça, na média geral de todos os lotes participantes do estudo.

Ao avaliar a correlação entre lotes com animais de diferentes categorias e sexos, Huertas et al. (2010) não detectaram influências significativas no aumento de lesões. No presente estudo não foram avaliados lotes compostos por categorias e sexos distintos. Quando analisadas as categorias, em associação com o sexo dos animais destinados ao abate (lotes homogêneos), foram formados três grupos de acordo com a disponibilidade de lotes: machos jovens (MJ), fêmeas jovens (FJ) e fêmeas adultas (FA). Não foi 
possível realizar a avaliação de machos adultos (MA) devido à insuficiência de lotes avaliados, por esta categoria não ser o perfil desejado pelos estabelecimentos para o abate.

Os grupos avaliados diferiram estatisticamente quando comparados pelo Teste Tukey. O grupo MJ, com 45,11\%, apresentou o menor percentual de carcaças lesionadas, contra 63,20\% e 94,82\% de carcaças com lesões, dos grupos FJ e FA, respectivamente. Estudo realizado na África, por Hoffman \& Lühl (2012), ao avaliar 5.257 bovinos, encontrou resultados semelhantes, com maior quantidade de lesões em novilhas, comparadas aos machos e contusões mais severas em vacas, sendo dessa categoria $83 \%$ das carcaças condenadas por lesões.

No centro-oeste brasileiro, com predomínio de raças zebuínas, Franco (2013) verificou frequências elevadas de contusões em lotes mistos e lotes de fêmeas, significativamente maiores que em lotes compostos por machos, e Nicholson (2008) verificaram a ocorrência de 65,8\% de fêmeas e 50,8\% de machos contundidos. Roeber et al. (2001) relataram $88,2 \%$ de carcaças lesionadas quando avaliadas vacas em estudo feito nos Estados Unidos.

Os estudos apresentados confirmam maior frequência de lesões em fêmeas, com prevalência superior em fêmeas adultas. De acordo com Rebagliati et al. (2008), as vacas apresentam proeminências ósseas mais expostas, maior peso e tamanho, enquanto Ghezzi et al. (2008) relatam maior frequência de animais aspados, restrições alimentares e comportamento de monta durante o cio, idade avançada de abate, além da maior reatividade como fatores influentes na ocorrência aumentada de lesões em vacas.

Ao comparar a severidade das lesões em seus graus de ocorrência (Tabela 1), o grupo MJ obteve índices significativamente menores que o grupo FA, apresentando $42,85 \%$ das carcaças com lesões GI, 2,26\% de GII e nenhuma incidência de lesões GIII. O grupo FJ apresentou 55,76 de lesões GI, não diferindo dos grupos FA e MJ. As contusões GII, representando 11,17\% e as lesões GIII, $0,46 \%$, foram estatisticamente semelhantes ao grupo MJ. Com maior frequência de lesões em todos os graus de severidade, as fêmeas adultas (FA) apresentaram 66,72\% das carcaças com lesões GI, 40,96\% com lesões GII e 2,87\% com lesões GIII.

Tabela 1. Classificação das lesões por Categorias/Sexo.

\begin{tabular}{lcccc}
\hline \multirow{2}{*}{ Categorias } & $\begin{array}{c}\text { C/Lesões } \\
\text { \% Médio (DP) }\end{array}$ & $\begin{array}{c}\text { Lesões GI } \\
\% \text { Médio (DP) }\end{array}$ & $\begin{array}{c}\text { Lesões GII } \\
\% \text { Médio (DP) }\end{array}$ & $\begin{array}{c}\text { Lesões GIII } \\
\% \text { Médio (DP) }\end{array}$ \\
\hline MJ & $45,11( \pm 14,05)^{\mathrm{c}}$ & $42,85( \pm 13,43)^{\mathrm{b}}$ & $2,26( \pm 4,14)^{\mathrm{b}}$ & $0,00( \pm 0,00)^{\mathrm{b}}$ \\
\hline FJ & $63,20( \pm 24,69)^{\mathrm{b}}$ & $55,76( \pm 16,51)^{\mathrm{ab}}$ & $11,17( \pm 9,66)^{\mathrm{b}}$ & $0,46( \pm 1,6)^{\mathrm{b}}$ \\
\hline FA & $94,81( \pm 5,13)^{\mathrm{a}}$ & $66,72( \pm 17,52)^{\mathrm{a}}$ & $40,96( \pm 18,72)^{\mathrm{a}}$ & $2,87( \pm 3,04)^{\mathrm{a}}$ \\
\hline DP
\end{tabular}

DP: Desvio Padrão; MJ: Machos Jovens; FJ: Fêmeas Jovens; FA: Fêmeas Adultas.

${ }^{a, b}$ Letras diferentes nas colunas indicam diferença estatística entre os grupos pelo Teste Tukey $(\mathrm{P}<0,05)$.

As perdas na etapa de toalete, para o grupo FA, foram significativamente superior aos demais grupos no dianteiro, costela/lombo e traseiro, totalizando perdas de $263 \mathrm{~g}, 367 \mathrm{~g}$ e $339 \mathrm{~g}$, respectivamente, com perda total de $970 \mathrm{~g}$ por animal abatido, contra $165 \mathrm{~g}$ do grupo FJ e $74 \mathrm{~g}$ do grupo MJ, conforme demonstrado na Tabela 2.

Tabela 2. Perdas médias (g/carcaça) na toalete por Categoria/Sexo.

\begin{tabular}{|c|c|c|c|c|}
\hline Categorias & $\begin{array}{c}\text { Dianteiro } \\
\text { g/carcaça (DP) }\end{array}$ & $\begin{array}{l}\text { Costela/Lombo } \\
\text { g/carcaça (DP) }\end{array}$ & $\begin{array}{c}\text { Traseiro } \\
\text { g/carcaça (DP) }\end{array}$ & $\begin{array}{l}\text { Total/Carcaça } \\
\text { g/carcaça (DP) }\end{array}$ \\
\hline $\mathrm{MJ}$ & $7,8( \pm 8,3)^{\mathrm{b}}$ & $25,1( \pm 21,1)^{\mathrm{b}}$ & $42,0( \pm 27,2)^{b}$ & $74( \pm 45,1)^{b}$ \\
\hline FJ & $36,5( \pm 48,2)^{\mathrm{b}}$ & $67,2( \pm 38,5)^{\mathrm{b}}$ & $61,8( \pm 19,41)^{b}$ & $165( \pm 83,8)^{\mathrm{b}}$ \\
\hline FA & $263( \pm 204,3)^{\mathrm{a}}$ & $367,3( \pm 263,9)^{\mathrm{a}}$ & $339,4( \pm 175,3)^{\mathrm{a}}$ & $970( \pm 543,2)^{\mathrm{a}}$ \\
\hline
\end{tabular}

DP: Desvio Padrão; MJ: Machos Jovens; FJ: Fêmeas Jovens; FA: Fêmeas Adultas.

a,b Letras diferentes nas colunas indicam diferença estatística entre os grupos pelo Teste Tukey $(\mathrm{P}<0,05)$.

A presença de chifres nos lotes não apresentou influência significativa na variação das lesões nas carcaças para lotes de mesmo sexo e faixa etária, com exceção dos grupos de fêmeas jovens, em que as fêmeas jovens aspadas (FJA) apresentaram 91,66\% de carcaças lesionadas, contra 54,41\% do grupo fêmeas jovens mochas $(\mathrm{FJM})$. Diferenças significativas $(\mathrm{P}<0,05)$ foram detectadas na ocorrência de lesões moderadas (GII), em que o grupo FJM apresentou menor índice de lesões, 5,61\%, contra 22,22\% 
no grupo FJA, confirmando a maior incidência de lesões de severidade superior nos lotes aspados, especialmente no quarto dianteiro, no qual as lesões ocasionaram perdas de 111,11 g em média, contra $16,62 \mathrm{~g}$ de média nos lotes compostos por animais mochos, diferindo estatisticamente. As demais variações foram devidas às categorias e sexo, não representativas para a característica física estudada.

Em estudo realizado no Rio Grande do Sul, comparando lotes de animais aspados (>20\% aspados) e lotes mistos $(<20 \%)$ Mendonça et al. (2016b) confirmaram maiores perdas econômicas por contusões em animais aspados, com frequência e gravidade superior nas costelas. Na toalete, o prejuízo médio por carcaça do grupo FJA foi de 277,92 g, estatisticamente superior $(\mathrm{P}<0,05)$, aos $130,18 \mathrm{~g}$ retirados em média do grupo FJM. Huertas et al. (2010) identificaram correlação positiva entre a presença de 1 animal aspado na carga e a aumento da ocorrência de hematomas.

O sistema de terminação, confinado ou não confinado, não influenciou na ocorrência, gravidade, distribuição ou quantidade das lesões nos lotes avaliados, tanto para machos jovens, quanto para fêmeas jovens. Não foram acompanhados lotes suficientes de machos e fêmeas adultos para possibilitar análise estatística referente ao sistema de terminação. O manejo de engorda adotado pode apresentar reflexos no temperamento e no comportamento dos animais nas etapas de manejo pré-abate, sendo o uso de métodos agressivos de condução e instrumentos inadequados, responsável pelo aumento na ocorrência, frequência e gravidade das contusões (Mendonça et al., 2016b). O uso de instrumentos pontiagudos em currais, carga e descarga de animais geram perdas na qualidade da carne produzida, sendo o bastão elétrico, de acordo com Rebagliati et al. (2008) grande causa de ocorrência de lesões nas propriedades e no transporte devendo tal método ser utilizado somente em situações de exceção.

Não foram constatados efeitos da distância no aumento da frequência, gravidade ou peso das lesões através da análise de correlação para nenhum dos grupos estudados, assim como no estudo realizado por Cardoso et al. (2011), no qual a distância entre as propriedades de origem dos animais e o abatedouro não teve relação significativa com os resultados, mesmo com alta frequência de lesões nas carcaças. Almeida et al. (2008) também não relata interferência, especialmente para distâncias inferiores a 100 $\mathrm{km}$.

Em estudo realizado na região do Pantanal, Andrade et al. (2008) perceberam que o aumento da frequência e gravidade de lesões tornou-se evidente em carcaças oriundas de propriedades com estradas em condições inadequadas, ou de animais submetidos a mais de uma modalidade de transporte, não apresentando relação direta e exclusiva com a distância. Huertas et al. (2010) relataram aumento da frequência e intensidade de perdas por contusões, devido a influência da condição das estradas, em estudo realizado no Uruguai, com distâncias médias de $240 \mathrm{~km}$ das propriedades ao frigorífico e tempos de viagens superiores a cinco horas. No presente estudo os tempos de transporte foram reduzidos, com estradas de rodagem em condições satisfatórias (asfaltadas em sua maioria), com distâncias médias de transporte de $130 \mathrm{~km}( \pm 82 \mathrm{~km})$.

Tabela 3. Influência dos fatores predisponentes na frequência, distribuição, gravidade e volume de contusões nos lotes avaliados.

\begin{tabular}{lccccc}
\hline Grupo & $\begin{array}{c}\text { C/Lesões } \\
\%(D P)\end{array}$ & $\begin{array}{c}\text { Perdas Diant. } \\
\text { g/carc. (DP) }\end{array}$ & $\begin{array}{c}\text { Perdas Cost. } \\
\text { g/carc. (DP) }\end{array}$ & $\begin{array}{c}\text { Perdas Tras } \\
\text { g/carc. (DP) }\end{array}$ & $\begin{array}{c}\text { Total } \\
\text { g/carc. (DP) }\end{array}$ \\
\hline MJE & $42,62( \pm 12,90)^{\mathrm{b}}$ & $7,2( \pm 9,3)^{\mathrm{b}}$ & $24,3( \pm 24,6)^{\mathrm{b}}$ & $37,59( \pm 25,1)^{\mathrm{b}}$ & $69,08( \pm 45,3)^{\mathrm{b}}$ \\
$\overline{\text { MJM }}$ & $59,05( \pm 21,28)^{\mathrm{b}}$ & $50,4( \pm 80,7)^{\mathrm{a}}$ & $40,2( \pm 28,6)^{\mathrm{b}}$ & $53,86( \pm 33,0)^{\mathrm{b}}$ & $144,53( \pm 127,9)^{\mathrm{b}}$ \\
\hline FJE & $63,72( \pm 23,89)^{\mathrm{b}}$ & $40,2( \pm 47)^{\mathrm{ab}}$ & $67,8( \pm 41,5)^{\mathrm{a}}$ & $59,01( \pm 21,1)^{\mathrm{b}}$ & $167,11( \pm 89,2)^{\mathrm{b}}$ \\
$\overline{\text { FJM }}$ & $67,85( \pm 25,25)^{\mathrm{a} \mathrm{b}}$ & $53,8( \pm 36,7)^{\mathrm{a} b}$ & $80,5( \pm 40)^{\mathrm{ab}}$ & $72,44( \pm 21,1)^{\mathrm{b}}$ & $206,73( \pm 97,9)^{\mathrm{a} b}$ \\
\hline MAM & $82,68( \pm 8,78)^{\mathrm{a}^{\mathrm{b}}}$ & $154,2( \pm 93,9)^{\mathrm{a} \mathrm{b}}$ & $74,7( \pm 25,9)^{\mathrm{ab}}$ & $63,57( \pm 46,7)^{\mathrm{b}}$ & $292,48( \pm 166,5)^{\mathrm{ab}}$ \\
\hline FAE & $94,03( \pm 5,64)^{\mathrm{a}}$ & $227,3( \pm 259)^{\mathrm{a}}$ & $358,7( \pm 281,3)^{\mathrm{a}}$ & $265,33( \pm 157,1)^{\mathrm{a}}$ & $851,35( \pm 591,2)^{\mathrm{a}}$ \\
\hline FAM & $95,48( \pm 5,50)^{\mathrm{a}}$ & $279,9( \pm 61,2)^{\mathrm{a}}$ & $273,5( \pm 149,1)^{\mathrm{a}}$ & $373,78( \pm 21,2)^{\mathrm{a}}$ & $927,20( \pm 106,8)^{\mathrm{a}}$ \\
\hline
\end{tabular}

DP: Desvio Padrão; MJE: Macho Jovem Europeu (182), MJM: Macho Jovem Misto (105), MAM: Macho Adulto Misto (35), Fêmea Jovem Europeia (200), FJM: Fêmea Jovem Mista (39), FAE: Fêmea Adulta Europeia (130), FAM: Fêmea Adulta Mista (70); MJNC. ${ }^{\mathrm{a}, \mathrm{b}}$ Letras diferentes nas colunas indicam diferença estatística entre os grupos pelo Teste Tukey $(\mathrm{P}<0,05)$.

$\mathrm{O}$ padrão racial dos lotes abatidos não influenciou significativamente $(\mathrm{P}>0,05)$ na ocorrência $\mathrm{e}$ gravidade das contusões, sendo as diferenças com significância estatística (Tabela 3), devidas às 
diferentes categorias e gêneros dos animais abatidos. No entanto, os lotes mistos, compostos por animais zebuínos, e/ou suas cruzas, apresentaram como regra, maior percentual de animais lesionados e maiores perdas nas áreas do dianteiro, traseiro e costela, assim como maiores perdas médias na totalidade das lesões. Como única exceção, as fêmeas adultas europeias (FAE) apresentaram maiores perdas no dianteiro em relação às fêmeas adultas mistas (FAM). Em estudo com animais anelorados, no Tocantins, Ferreira et al. (2010) observaram maiores perdas devido ao temperamento, questões de dominância e agressões diretas de lotes de origem zebuína. Mendonça et al. (2016b) também relata maior susceptibilidade deste grupo genético à contusões devido a excitabilidade.

O conjunto de dados apresentados permitiu traçar um diagnóstico da ocorrência de lesões, bem como das perdas para as diferentes categorias animais abatidas no estabelecimento, fornecendo subsídios para orientação de produtores, adequação da política de remuneração e identificação de fatores que predispõem os animais à perdas por contusões.

\section{Conclusões}

No presente estudo, as fêmeas apresentaram maiores perdas em relação aos machos e destas, as fêmeas adultas tiveram prejuízos significativamente maiores que em lotes de animais jovens, demonstrando que as categorias animais e gênero são os principais fatores determinantes para a variabilidade da ocorrência, severidade e classificação das lesões.

Os Machos jovens apresentam perdas inferiores aos demais grupos estudados e a presença de animais aspados (>20\%) apresentou-se como fator significativo no aumento de perdas por contusões para grupos de fêmeas jovens. A distância de transporte, o sistema de terminação e o padrão racial dos animais não foram significativos na alteração da severidade, classificação e frequência de lesões.

Existe uma relação direta da ocorrência de lesões com o manejo pré-abate, boas práticas agropecuárias e características temperamentais, variando em intensidade, com o manejo empregado em cada propriedade, de acordo com a infraestrutura e condições apropriadas de bem estar, as quais foram consideradas como satisfatórias, de acordo com os requisitos estabelecidos pela legislação, para este estudo.

\section{Referências}

Almeida, L. A. M., Prata, L. F., Fukuda, R. T., \& Verardino, H. (2008). Manejo pré-abate de bovinos: monitoração de bem-estar animal em frigoríficos exportadores perdas econômicas por contusões. Hig. Aliment, 80-87.

Andrade, E N, Silva, R., \& Roça, R. O. (2009). Manejo pré-abate de bovinos de corte no pantanal, Brasil. Archivos de Zootecnia, 58(222), 301-304.

Andrade, Ernani Nery, Silva, R. A. M. S., Roça, R. O., Silva, L. A. C., Gonçalves, H. C., \& Pinheiro, R. S. B. (2008). Ocorrência de lesões em carcaças de bovinos de corte no Pantanal em função do transporte. Ciência Rural, 38(7), 1991-1996.

Braggion, M., \& Silva, R. (2004). Quantificação de lesões em carcaças de bovinos abatidos em frigoríficos no Pantanal Sul-Mato-Grossense. Embrapa Pantanal.

Cardoso, M. R. P., Moura, M. S., \& Moreira, M. D. (2011). Ocorrência de contusões em carcaças bovinas abatidas em um matadouro-frigorífico de Uberlândia-MG. PUBVET, 5, Art-1026.

Civeira, M. P., Renner, R. M., Vargas, R. E. S., \& Rodrigues, N. C. (2006). Avaliação do bem-estar animal em bovinos abatidos para consumo em frigorífico do Rio Grande do Sul. Revista Veterinária Em Foco, 4(1), 5-11.

Costa, M. J. R. P., Zuin, L. F. S., \& Piovesan, U. (1998). Avaliação preliminar do manejo pré-abate de bovinos no programa de qualidade da carne bovina do Fundepec. Relatório Técnico, 21.

Dario, R. H. Z. (2008). Avaliação do bem-estar animal de bovinos abatidos em frigorífico de Bauru-SP. In IV Simpósio de Ciências da Unesp e V Encontro de Zootecnia. Dracena, SP.

Ferreira, J. L., Cavalcante, T. V., Marinho, J. P., Lopes, F. B., \& Minharro, S. (2010). Influência Do Manejo Pré-abate na produção de carne bovina no município de Araguaína, Tocantins. Revta Cient. Eletrôn. Med. Vet, 8, 15. 
Franco, M. R. (2013). Caracterização do transporte rodoviário de bovinos de corte e efeitos no bemestar animal e na qualidade as carcaças [Dissertação (mestrado) - Universidade Estadual Paulista Júlio de Mesquita Filho, Faculdade de Ciências Agrárias e Veterinárias]. http://hdl.handle.net/11449/96520

Ghezzi, M. D., Acerbi, R., Ballerio, M., Rebagliatti, J. E., Díaz, M. D., Bergonzelli, P., Civit, D., Rodríguez, E. M., Passucci, J. A., \& Cepeda, R. (2008). Evaluación de las prácticas relacionadas con el transporte terrestre de hacienda que causan perjuicios económicos en la cadena de ganados y carne. IPCVA, Cuadernillo Técnico, 5.

Grandin, T. (1996). Factors that impeded animal movement at slaughter plants. Journal of American Veterinary Medical Association, 209, 757-759.

Hoffman, D. E., Spire, M. F., Schwenke, J. R., \& Unruh, J. A. (1998). Effect of source of cattle and distance transported to a commercial slaughter facility on carcass bruises in mature beef cows. Journal of the American Veterinary Medical Association, 212(5), 668-672. http://europepmc.org/abstract/MED/9524638

Hoffman, L. C., \& Lühl, J. (2012). Causes of cattle bruising during handling and transport in Namibia. Meat Science, 92(2), 115-124. https://doi.org/http://dx.doi.org/10.1016/j.meatsci.2012.04.021

Huertas, S. M., Gil, A. D., Piaggio, J. M., \& Van Eerdenburg, F. (2010). Transportation of beef cattle to slaughterhouses and how this relates to animal welfare and carcase bruising in an extensive production system. Animal Welfare, 19(3), 281-285.

Mendonça, F. S., Vaz, R. Z., Costa, O. A. D., Gonçalves, G. V. B., \& Moreira, S. M. (2016a). Fatores que afetam o bem-estar de bovinos durante o período pré-abate. Archivos de Zootecnia, 65(250), 279-287. https://doi.org/10.21071/az.v65i250.500

Mendonça, Fábio Souza, Vaz, R. Z., Leal, W. S., Restle, J., Pascoal, L. L., Vaz, M. B., \& Farias, G. D. (2016b). Genetic group and horns presence in injuries and economic losses of bovine carcasses. Semina: Ciências Agrárias, 37(6), 4265. https://doi.org/10.5433/1679-0359.2016v37n6p4265

Nicholson, J. D. W. (2008). National market cow and bull beef quality audit-2007: a survey of producerrelated defects. 2008 [(Doctoral dissertation, Dissertation (Master of Science in Animal Science)-Ofice of Graduate Studies Texas A \& M Imoversity: College Stadio).]. https://core.ac.uk/download/pdf/4276759.pdf

Rebagliati, J. E., Ballerio, M., Acerbi, R., Mauricio, D., Alvarez, M. M., Bigatti, F., Cruz, J. A., Scitelli, L., Ergonzelli, P., \& Gonzalez, C. (2008). Evaluación de las prácticas ganaderas en bovinos que causan perjuicios económicos en plantas frigoríficas de la República Argentina (2005). REDVET. Revista Electrónica de Veterinaria, 9(10B), 1-40.

Renner, R. M. (2005). Fatores que afetam o comportamento, transporte, manejo e sacrifício de bovino. Tese de Doutorado. Tese de Especialização em Tecnologia dos Produtos de Origem Animal, Universidade Federal do Rio Grande do Sul, Porto Alegre.

Roeber, D. L., Mies, P. D., Smith, C. D., Belk, K. E., Field, T. G., Tatum, J. D., Scanga, J. A., \& Smith, G. C. (2001). National market cow and bull beef quality audit—1999: a survey of producer-related defects in market cows and bulls. Journal of Animal Science, 79(3), 658-665. https://doi.org/10.2527/2001.793658x

Valor Econômico. (2019). Exportações de carne bovina cresceram 10\% e bateram recorde em 2018. https://valor.globo.com/agronegocios/noticia/2019/01/07/exportacoes-de-carne-bovina-cresceram10-e-bateram-recorde-em-2018.ghtml

\section{Histórico do artigo:}

Recebido: 23 de junho de 2020 Aprovado: 1 de outubro de 2020 Disponível online: 26 de novembro de 2020.
Licenciamento: Este artigo é publicado na modalidade Acesso Aberto sob a licença Creative Commons Atribuição 4.0 (CC-BY 4.0), a qual permite uso irrestrito, distribuição, reprodução em qualquer meio, desde que o autor e a fonte sejam devidamente creditados. 